\title{
A CONTRADIÇÃO EXCLUSÃO/INCLUSÃO NA SOCIEDADE E NA ESCOLA
}

\author{
CONTRADICTION EXCLUSION/INCLUSION \\ IN SOCIETY AND IN THE SCHOOL \\ CONTRADICTION EXCLUSION/INCLUSION \\ DANS LA SOCIÉTÉ ET À L'ÉCOLE \\ LA CONTRADICCIÓN EXCLUSIÓN/INCLUSIÓN \\ EN LA SOCIEDAD Y EN LA ESCUELA
}

\author{
Regina Vinhaes Gracindo * \\ Sonirza Correa Marques ** \\ Olgamir Amância Ferreira de Paiva ***
}

\begin{abstract}
RESUMO
Com o entendimento de que a desigualdade social e a concentração de renda no Brasil vêm se acentuando e assumindo formas cada vez mais perversas de exclusão social, o presente artigo tem por objetivo refletir sobre o processo de exclusão na sociedade, em geral, e na educação, em particular. Para tanto, procurou identificar algumas interpretaçōes dadas ao termo exclusão, identificando-o como uma contradição no movimento histórico do sistema capitalista. Além disso, buscou verificar como essa contradição que se implanta na modernidade, manifesta-se no campo da educação, sobretudo, no final do século XX e início do século XXI. Tal como nas politicas públicas globais do Estado, identificou-se o sentido de exclusão subjacente às políticas de educação, como instrumento de mediação para assegurar a estrutura de classes da sociedade capitalista. Procurando identificar políticas públicas de educação básica que visam à inclusão social, surgem alguns programas voltados para o atendimento à população carente, com o objetivo de inserir e manter essa população no sistema educacional, com destaque ao Programa BolsaEscola Federal, que se conforma como uma ação para garantia de renda mínima.
\end{abstract}

Palavras-chave: Exclusão social. Exclusão escolar. Políticas públicas. Políticas de educação.

* Doutora em Educação pela Universidade de São Paulo (USP, 1993). Professora Adjunta IV da Faculdade de Educação e do Programa de Pós-Graduação em Educação da Universidade de Brasília - UnB (reginagracindo@globo.com).

** Mestre em Educação pela UnB. Professora da Secretaria de Estado da Educação do Distrito Federal - SEE-DF (SonirzaMarques@aol.com).

*** Mestre e Doutoranda pelo Programa de Pós-Graduação em Educação da UnB. Professora da SEE-DF (olgamancia@brturbo.com.br). 


\section{INTRODUÇÃO}

O Brasil tem se caracterizado historicamente por dois traços significativos: uma enorme desigualdade social e uma alarmante concentração de renda. Essas características vêm se acentuando e assumindo formas cada vez mais perversas de exclusão social.

A exclusão social no Brasil é facilmente identificada quando dados do IBGE (2000) indicam que: há 21 milhôes de indigentes e 50 milhões de pobres formando um contingente onde mais de $40 \%$ da população está excluída dos bens econômicos, políticos e sociais; dos trabalhadores brasileiros com mais de 10 anos, 65,2\% recebem somente até dois salários mínimos (IBGE, 2003); e que o rendimento do trabalho prossegue reduzindo com índices de $-7,5 \%$ em relação a 2002 (IBGE, 2004).

Esse panorama excludente tem reflexos importantes também no campo da educação. Dados educacionais reforçam essa assertiva, ao identificarem que, da população com mais de sete anos, $11,2 \%$ são analfabetos, dos quais aproximada-mente dois milhões e quinhentos mil estão na faixa de escolaridade obrigatória ( 7 a 14 anos). Dentre os maiores de 10 anos, $11,2 \%$ não têm escolaridade ou estiveram na escola pelo período de até um ano; $27,5 \%$ têm até três anos de escolaridade e mais de $2 / 3$ da população $(60,4 \%)$ não possuem o ensino fundamental completo, tendo, no máximo, sete anos de escolaridade (IBGE, 2003).

Analisar a questão da exclusão/inclusão na sociedade, em geral, e na educação, em particular, implica em dimensioná-la em termos históricos e de forma contextualizada. Nesse sentido, cabe aqui refletir sobre: a) algumas interpretações dadas ao termo exclusão social; b) a exclusão social no sistema capitalista; c) a exclusão social no campo da educação; d) as políticas públicas e o sentido de inclusão/exclusão escolar.

\section{EXCLUSÃO SOCIAL: ALGUMAS INTERPRETAÇÕES}

O termo exclusão vem do latim exclusione e significa o "ato de excluir(-se); exceção. Ato pelo qual alguém é privado ou excluído de determinadas funçōes" (FERREIRA, 1999, p. 857). Sustentando-se nesta definição, Nascimento (1994, p. 2) identifica exclusão social como "a ação ou efeito de colocar à margem um ou vários indivíduos. Supressão que pode ser de direitos e/ou do acesso a bens ou serviços, tanto materiais quanto simbólicos".

O termo exclusão social tem se apresentado com significados muito variados, conceituando diferentes situações de carência, discriminação, vulnerabilidade, dentre outros. Escorel (1998, p. 1), ao analisar as várias abordagens que conduzem a uma ampla utilização do termo, permitindo que este possa "designar toda situação ou condição social de carência, dificuldade de acesso, segregação, discriminação, vulnerabilidade e precariedade em qualquer âmbito", indica que um termo com tal abrangência, ao definir tudo, acaba por não definir nada.

Da mesma forma, outras concepções teóricas demonstram a desconfiança provocada pela amplitude conceitual dada ao termo, reafirmadas por Castel (2000), ao assegurar que, ao ser utilizado para conceituar tantas coisas diferentes, acaba por "encobrir a especificidade de cada uma”, e, ao não descortinar o seu objeto, obstaculiza a investigação e a análise dos conteúdos os quais abrange. 
Autores que se dedicam à reflexão da questão da exclusão social, em geral, entendem que há uma diferença entre a exclusão social originada na esfera produtiva e a derivada das questôes culturais e de cidadania. Outros consideram que "na esfera produtiva não existe exclusão, mas exploração, causada pela inserção desigual dos sujeitos sociais na produção" (BONETI, 1998, p. 11). Neste sentido, Martins (1997) compreende que:

Rigorosamente falando não existe exclusão: existe contradição, existem vítimas de processos sociais, políticos e econômicos excludentes; existe o conflito pelo qual a vítima dos processos excludentes proclama seu inconformismo, seu mal-estar, sua revolta, sua esperança, sua força reivindicativa e sua reivindicação corrosiva. Essas reaçōes, porque não se trata estritamente de exclusão, não se dão fora dos sistemas econômicos e dos sistemas de poder. Elas constituem o imponderável de tais sistemas, fazem parte deles, ainda que os negando. As reações não ocorrem de fora para dentro; elas ocorrem no interior da realidade problemática, 'dentro' da realidade que produziu os problemas que a causam (p. 14).

Entretanto, autores como Sawaia (2001), ainda que reconhecendo a imprecisão e a dubiedade conceitual, optam por aprimorá-lo, procurando explicitar as ambigüidades internalizadas no conceito, entendendo que essas ambigüidades "não revelam erro ou imprecisão, mas a complexidade e a contraditoriedade que constituem o processo de exclusão social” (p. 7). Assim, procura compreender a exclusão numa concepção dialética exclusão/inclusão, processo que gesta subjetividades específicas e que não encontra explicações apenas nas relações econômicas.

A exclusão é processo complexo e multifacetado, uma configuração de dimensões materiais, políticas, relacional e subjetiva. É processo sutil e dialético, pois só existe em relação à inclusão como parte constitutiva dela. Não é uma coisa ou um estado, é processo que envolve o homem por inteiro e suas relações com os outros. Não tem uma única forma e não é uma falha do sistema; devendo ser combatida como algo que perturba a ordem social, ao contrário, ele é produto do funcionamento do sistema (2001, p. 9).

Assim, a exclusão/inclusão social como processo histórico deve ser entendida como um contínuo incluir/excluir num processo relacional e mutável. A inclusão social, desta forma, "deve ser fundada num paradigma de ética e justiça social, pois é econômica, social, política e cultural, logo, multifacetada" (SPOSATI, 2001, p. 77). A autora propóe pensar a exclusão a partir da distância e discrepância do que se entende por inclusão. Nesse sentido, a idéia de inclusão transcende os liames do mercado, embora parte das necessidades humanas seja satisfeita no mercado.

Aproximando o termo exclusão ao de pobreza, Sposati (1999, p. 66), indica para esse último o caráter econômico, de salário, renda, capacidade de consumo, indicando que o indivíduo está privado de um mínimo de condiçôes de vida, de outro lado, delimita que "a exclusão comporta valores culturais, discriminações". Observada sob o olhar da pobreza, a questão da exclusão social assume características de questão social, especialmente com as mudanças no setor produtivo e no mundo do trabalho, ocorridas a partir de 1980, o que tem levado ao empobrecimento de um grande contingente populacional. Castel (2001, p. 18) assim define questão social: 
é uma aporia fundamental sobre a qual uma sociedade experimenta o enigma de sua coesão e tenta conjurar o risco de sua fratura. Ela é um desafio que interroga, põe em questão a capacidade de uma sociedade de existir como um conjunto ligado por relaçōes de interdependência.

Castel (2000, p. 24) afirma ainda que a exclusão nomeia, atualmente, "situações que traduzem uma degradação relacionada a um posicionamento anterior", promovendo uma situação de vulnerabilidade de quem vive do trabalho precário. Para o autor, o termo exclusão "designa muito mais os efeitos", não abarca os "fatores que precedem a exclusão"; logo, pode-se falar em precarização, vulnerabilização, marginalização. Dessa forma, o referido autor acredita que o termo desafiliação traduz melhor esse estado de coisas, pois, refletindo a partir dos eixos de integração/desintegração do mundo do trabalho e do mundo das relaçôes sociais, ele afirma que:

a precariedade e instabilidade dos vínculos do mundo do trabalho formal produzem contingentes populacionais desnecessários. No mundo das relações sociais a fragilização dos vínculos pode produzir rupturas que conduzem ao isolamento social e à solidão.

Nesse mesmo sentido, Paugam (1999) sinaliza que qualquer tentativa de definição estática da pobreza acaba por agrupar populaçōes que vivenciam situações heterogêneas, o que leva muito mais a ocultar do que revelar a origem e os efeitos de um processo que vem se desenrolando. Nessa análise, o autor propôs o conceito de desqualificação social que, em sua visão, abarca melhor a complexidade e a multidimensionalidade do "movimento de expulsão gradativa, para fora do mercado de trabalho, de camadas cada vez mais numerosas da população". Segundo ele, a "precariedade da vida profissional está relacionada com a diminuição da sociabilidade", num mecanismo de enfraquecimento dos vínculos sociais e a conseqüente fragilidade e dependência. À fase de dependência se segue outra, caracterizada pela ruptura dos vínculos sociais com a família, com o grupo de amigos e com a relação profissional.

$\mathrm{Na}$ análise que faz da estrutura excludente em que a sociedade brasileira está assentada, Buarque propõe a noção de apartação social para designar o processo de separação vivenciado pelos indivíduos vitimados pela pobreza. Para ele, apartação social designa um processo pelo qual denomina-se o outro como um "ser à parte". O fenômeno de "aceitação da miséria ao lado da riqueza, separação de classes, consolidação dos privilégios, exclusão" (1999, p. 72). E esta é uma forma contundente de intolerância social.

$\mathrm{Na}$ concepção de Sposati (1999, p. 67), a exclusão social não é "processo individual, embora atinja pessoas". Trata-se de uma lógica assentada nas diversas formas de relaçôes econômicas, sociais, culturais e políticas. Assim, como

fenômeno composto por múltiplos elementos, [...] a exclusão social é a impossibilidade de poder partilhar. O que leva à vivência da privação, da recusa, do abandono e da expulsão, inclusive com violência, de um conjunto significativo da população. Por isso é uma exclusão social e não pessoal.

Pensar sobre exclusão/inclusão social significa, pois, pensá-la como fenômeno inserido nas relações de produção capitalista no seu movimento de manutenção/renovação/transformação, uma vez que, conforme Marx (1976, p. 98), o modo de produção capitalista é estruturalmente excludente, o aumento da indigência decorre da luta 
pelo desenvolvimento do capitalismo, pois “... nas mesmas relaçōes nas quais se produz a riqueza, também se produz a miséria; nas mesmas relações nas quais há desenvolvimento das forças produtivas, há uma força produtora de repressão".

\section{A EXCLUSÃO SOCIAL E O SISTEMA CAPITALISTA}

Dentre os diversos conceitos de exclusão, há um entendimento de que ela é uma nova forma de manifestação da questão social que tem características específicas da conjuntura vigente, porém, com raízes fundadas num processo histórico que vem se desenvolvendo desde o início da industrialização. Nessa concepção, a exclusão está diretamente vinculada ao surgimento da sociedade moderna, e ao sistema político e econômico que rege esta sociedade, tendo em vista que na maior parte das sociedades antigas a exclusão não constituía um problema. O excluído era parte do cenário, a exclusão era naturalizada nas relações sociais de tais sociedades, a "exclusão encontrava-se inscrita na própria estrutura social” (NASCIMENTO, 1994, p. 2).

Nesse sentido, foi através da instituição da sociedade moderna que se modificou essa lógica de naturalização da exclusão, visto que ela surge como uma sociedade diferente de todas que a precederam, principalmente porque se ancora no princípio da "existência de um espaço de igualdade" (NASCIMENTO, 1994, p. 2). Portanto, nesta sociedade, a desigualdade explicitada no fenômeno da exclusão constituiu-se numa contradição. Tal contradição coloca em xeque tanto a sua definição de "sociedade movida pela lógica da integração social, vocacionada ao universal" (ibid.) quanto os argumentos utilizados para explicar a existência de desigualdades nesse contexto social, segundo os quais as desigualdades entre pessoas, países ou no interior destes, por mais profundas que fossem, representavam uma deformação passageira, que seria certamente superada com a modernização.

Entretanto, Marx (1984), na sua construção teórica sobre a acumulação capitalista e a relação desta com os destinos da classe trabalhadora, explicita que:

...a verdade é que a acumulação capitalista sempre produz, e na proporção da sua energia e de sua extensão, uma população trabalhadora supérflua relativamente, isto é, que ultrapassa as necessidades médias da expansão do capital, tornando-se desse modo, excedente (p. 730-731).

Ao analisar a conceituação e configuração do exército industrial de reserva à luz do pensamento marxiano, parece que a exclusão social fica mais facilmente delineada não como algo estanque, mas como processo inerente ao modo de produção capitalista, em que a provisoriedade, a precariedade, marcam as relaçóes no mercado de trabalho, de forma que os trabalhadores ora estão empregados, ora desempregados, e em outros momentos se encontram nos chamados subempregos, numa posição de vulnerabilidade constante, porém sempre alienando a sua força de trabalho como condição de sua sobrevivência.

Os indicadores sociais na atualidade demonstram que a tendência dessa contradição é acentuar-se gradativamente, pois a lógica que rege a sociedade capitalista é a lógica do lucro e da concentração da riqueza, é a lógica da diversificação da produção e da 
constante introdução de novos e variados produtos no mercado, e não a satisfação das demandas de sobrevivência da humanidade. Nessa linha de raciocínio, Buarque (1999), ao analisar o século $\mathrm{XX}$, assim se expressa:

No século atual, o processo econômico passou a oferecer variadas possibilidades de consumo, restritas apenas a uma parcela da população. Em vez de criar a abundância e satisfazer a necessidade dos mesmos e poucos produtos de antes, como muitos sonhavam, a industrialização ampliou a variedade de produtos e assim aumentou as necessidades, em vez de diminuí-las (p. 13).

Nesse debate fica claro que a exclusão social certamente não constitui um fenômeno novo. Ela é resultado das contradições engendradas pelo modo de produção capitalista. No entanto, como o capitalismo não se apresenta da mesma forma ao longo do tempo, e o seu desenvolvimento varia de uma região do planeta para outra, certamente há mudanças na forma como esse fenômeno se apresenta ao final do século XX, início do século XXI. Para entendê-lo com as nuances como se apresenta hoje, é preciso perceber o modo como se deu a nova conjuntura social, com uma parcela alijada do processo produtivo, porém, contraditoriamente, necessária a ele. Também importante é assinalar que a exclusão é "desencadeada por fatores econômicos" (CASTEL, 2000), é processual, e faz parte de uma mesma totalidade, por isto:

a perda do acesso à participação na dinâmica produtiva da sociedade implica, de conformidade com a estrutura social e política vigente, a exclusão dos direitos ao atendimento igualitário dos serviços sociais básicos, o que significa, também, a perda da cidadania (BONETI, 1998, p. 11).

Nesse sentido, o pensamento de Castel (2000) clareia a idéia de exclusão, ao identificar que os fatores econômicos provocam a perda do vínculo de integração social, conduzindo à conclusão de que o desemprego duradouro é determinante do processo de exclusão, e que esta tem sua origem no centro da vida social, e não na periferia desta, portanto, "os traços constitutivos essenciais das situações de 'exclusão' não se encontram nas situações em si mesmas" (p. 21). Ao remeter a exclusão à condição de resultante processual, o autor mostra a necessidade de se refletir sobre "as dinâmicas sociais globais" como condição para entender o fenômeno. Por isto, Castel (2000), ao estudar a exclusão, constrói uma abordagem a partir da constituição da sociedade salarial de forma processual, buscando na relação histórica ir além da identificação das pessoas apenas como integradas ou marginalizadas, mas, sobretudo, procurando entender os processos históricos que desencadeiam essas situações.

Os excluídos povoam a zona mais periférica, caracterizada pela perda do trabalho e pelo isolamento social. Mas o ponto essencial a destacar é que hoje é impossível traçar fronteiras nítidas entre essas zonas. Sujeitos integrados tornam-se vulneráveis, particularmente em razão da precarização das relaçôes de trabalho, e as vulnerabilidades oscilam cotidianamente para aquilo que chamamos de exclusão. Mas é preciso ver aí um efeito de processos que atravessam o conjunto da sociedade e se originam no centro e não na periferia da vida social (CASTEL, 2000, p. 23). 
Vale assinalar que, a partir de 1973, "o mundo capitalista avançado caiu numa crise caracterizada pela longa e profunda recessão, combinada a baixas taxas de crescimento, com altas taxas de inflação" (ANDERSON, 2000, p. 13), promovendo uma nova "configuração do capitalismo mundial e nos mecanismos que comandam seu desempenho e sua regulação" (CHESNAIS, 1996, p. 13), cuja origem, Antunes (2001, p. 38) encontra na "crise estrutural do capital, no desmoronamento do Leste Europeu e na crise da esquerda tradicional, que sofreu um agudo processo político de atuação subordinada ao capital".

Hobsbawm (1995, p. 393-394), por sua vez, refere-se à história dos 20 anos após 1973 como a "história de um mundo que perdeu suas referências e resvalou para a instabilidade e a crise". Crise que Hayek e seus seguidores explicam, segundo Anderson (2000, p. 10-11), como "localizadas no poder excessivo e nefasto dos sindicatos", pois o movimento operário teria "corroído as bases de acumulação capitalistas com suas pressões reivindicativas sobre os salários".

O modelo econômico que se instalou, na avaliação de Hobsbawm (1995), procura substituir a capacidade humana pela capacidade das máquinas, o trabalho humano por forças mecânicas, jogando com isso pessoas para fora dos empregos. Sob circunstâncias de desintegração social e política, assistimos ao crescente desemprego não simplesmente cíclico, mas estrutural, levando às reflexões de Forrester (1997, p. 11) de que:

Um desempregado, hoje, não é mais objeto de uma marginalização provisória, ocasional, que atinge apenas alguns setores; agora, ele está às voltas com uma implosão geral, um fenômeno comparável a tempestades, ciclones e tornados, que não visam ninguém em particular, mas aos quais ninguém pode resistir. Ele é objeto de uma lógica planetária que supõe a supressão daquilo que se chama trabalho; vale dizer, empregos.

Nesta "nova" fase do sistema capitalista, os direitos do trabalho são flexibilizados, desregulamentados, para assegurar ao capital condições de adaptação ao "novo".

Novos processos de trabalho emergem, onde o cronômetro e a produção em série e de massa são 'substituídos' pela flexibilização da produção, pela 'especialização flexível', por novos padrōes de busca de produtividade, por novas formas de adequação da produção à lógica do mercado (ANTUNES, 1995, p. 16).

O capitalismo assentado no receituário neoliberal exige que as relações de troca sejam postas como fim primeiro e último das relações sociais. O mercado passa a definir todas as regras na relação entre os homens: "todas as funções reprodutivas sociais - das relações de gênero familiares à produção material, incluindo até mesmo a criação das obras de arte", estão, segundo Antunes (2000), subordinadas "ao imperativo absoluto da expansão do capital" (p. 21); é a mais completa subordinação das necessidades humanas (consideradas limitadas) à reprodução do valor de troca.

As últimas décadas do século XX e a primeira década do século XXI foram e estão sendo caracterizadas por configurações e movimentos que vão além da internacionalização ou da transnacionalização; são movimentos e configurações de uma ordem mais ampla, 
que rompem as fronteiras de espaço e tempo, mediadas pelos avanços tecnológicos e informacionais: é a chamada globalização. Segundo Held e McGrew (2001):

o conceito de globalização denota muito mais do que a ampliação de relações e atividades sociais, atravessando regiōes e fronteiras. É que ele sugere uma magnitude ou intensidade crescente de fluxos globais, de tal monta que Estados e sociedades ficam cada vez mais enredados em sistemas mundiais e redes de interação (p. 12).

Sobre o processo designado por mundialização do capital e globalização, Chesnais (1996, p. 24) alerta que o termo 'globalizaçáo' tem sido utilizado sob uma perspectiva neutra, "para manipular o imaginário social e pesar nos debates políticos". Mundialização, para ele, é o resultado de dois movimentos distintos e interligados: acumulação ininterrupta de capital e as políticas de liberalização, privatização, desregulamentação e desmantelamento das conquistas sociais e democráticas, aumento brutal do desemprego, via apropriação da mais-valia, tanto absoluta como relativa (CHESNAIS, 1996, p. 34). Com isso, o autor demonstra que mundialização é o termo que melhor traduz os acontecimentos vivenciados, porque não é todo o planeta que interessa ao capital, mas parte dele, pois o capital recuperou sua capacidade de escolha entre regióes do planeta e as camadas sociais que interessam a seus propósitos, num mecanismo complementar e análogo ao da exclusão da esfera de atividade produtiva, que atinge uma parte da população dentro de cada país. Assim, pensar a exclusão social no contexto brasileiro implica identificar o Brasil nesse concerto mundializado, buscando, pelo menos, analisar nossas origens de sociedade colonizada e o papel periférico na economia mundial.

\section{A EXCLUSÃO SOCIAL NO CAMPO DA EDUCAÇÃO}

A questão social aparece, no caso brasileiro, atrelada à cultura da exclusão, que para Arroyo (2000, p. 12), é também identificada na organização e na estrutura do nosso sistema escolar. Cultura essa que "legitima práticas, rotula fracassados, trabalha com preconceitos de raça, gênero e classe, e que exclui".

Demonstrando a contradição que se implanta na modernidade, a exclusão manifestada no campo da educação, no final do século XIX e início do século XX, faz ampliar as pressōes populares por educação, que desempenham papel importante na expansão da rede escolar nos países capitalistas centrais, colocando a necessidade de explicar a diferença de rendimento e justificar o acesso desigual.

A questão que ora se coloca é: como essa diferença tem sido explicada?

$\mathrm{Na}$ concepção liberal, não se trata de preconizar uma sociedade na qual desaparecerão as desigualdades; trata-se de justificá-las no âmbito da desigualdade de oportunidades. No nível das idéias, a desigualdade social, inerente ao capitalismo, dá-se pela tradução das desigualdades sociais em desigualdades raciais, pessoais e culturais. Para Hobsbawm (1982, p. 315), a tendência de atribuir a pobreza a uma inferioridade inata e os piores abusos das teorias racistas só se darão após os anos cinqüenta do século XX. Para Patto (1999, p. 51), de outro lado, a adesão ao anticlericalismo e ao cientificismo permitiu que 
estereótipos e preconceitos raciais milenares adquirissem status de conhecimento neutro, objetivo, verdadeiro conferidos pela ciência experimental positivista.

Na medida em que a chamada Psicologia Diferencial (1940/1950) preconizava que as "pessoas eram portadoras de dons ou aptidōes inatas, inclusive inteligência, que as faziam ter maior ou menor sucesso na escola e na vida" (SILVA, 2000, p. 29), as explicaçôes para as diferenças de rendimento deixem de ser raciais e passam a ser culturais. Para Hobsbawm (1979), o mundo da classe média se abria a todos; os que não conseguiam atingi-lo demonstravam falta de inteligência pessoal, força moral ou de energia, herança cultural ou histórica que deveria invalidá-los eternamente.

$\mathrm{Na}$ década de 1960 , segundo Silva (2000, p. 29) os movimentos sociais das minorias deslocaram o foco das explicaçôes para aspectos culturais, dando ensejo às teorias da privação ou carência que propiciou o desenvolvimento da idéia de educação compensatória nas décadas de 1970/1980, que visavam minimizar as faltas que a criança carregava. Para Patto (1999), os programas educacionais especificamente destinados às crianças empobrecidas ratificaram o terreno do preconceito e dos estereótipos sociais.

A partir da obra de D’Ávila (1985), pode-se perceber que, nos anos de 1980, a questão da exclusão educativa passa a ser analisada na perspectiva da escola como aparelho ideológico do Estado, ${ }^{1}$ a serviço da dominação, especialmente pela violência simbólica. ${ }^{2}$ Com isso, o discurso passa a ser o da diferença, e não mais do déficit. Até então, as teorias identificavam a criança "não dotada", ou geneticamente "pouco inteligente", na teoria dos dons, com a criança das classes populares. $\mathrm{Na}$ teoria dos "déficits" existe uma coincidência entre as crianças portadoras de "carências" e as das classes populares. O que Althusser, Bourdieu e Passeron trazem como elemento novo é a relação do fracasso escolar com a relação de dominação, numa sociedade de classes.

O discurso é de que as crianças têm acesso diferenciado, em conseqüência da condição social, a um certo universo de conhecimentos, e que a escola privilegia o universo acessado pelas crianças das classes mais altas, através das práticas pedagógicas instituídas. Isso nos leva a pensar a exclusão educacional com um olhar mais global, extra-escolar. A exclusão educativa situa-se, assim, como expressão da lógica de exclusão que permeia os complexos processos de reprodução da lógica social presente nas instituições sociais.

Inserir a questão nos moldes do institucional que perpassa o sistema escolar, "situando nesse campo o instituído das instituições sociais que articulam, consolidam, reforçam lógicas, processos sociais e culturais" (ARROYO, 2000, p. 34) não pode significar imobilismo, mas sim uma atitude pró-ativa, promovendo o repensar da cultura de seletividade, reordenando o sistema escolar como um todo.

O que vale ressaltar é que qualquer abordagem histórica sobre a educação brasileira demonstra o seu caráter excludente, mostrando que a exclusão escolar se encontra inserida num universo de várias outras formas de exclusão social (econômica, política e cultural) e que tem raízes fundadas no processo de formação da sociedade. Verifica-se que, mesmo a exclusão escolar tendo se constituído numa marca permanente até os dias atuais, ela não se configurou ou se configura da mesma maneira ao longo do tempo. Em alguns momentos ela é explicitada pela negação do acesso à classe trabalhadora ao saber escolarizado, em outros, combinado ao acesso restrito, materializa-se uma outra forma de 
exclusão pela introdução de uma estrutura dual de escola, em que o poder público diferencia a escola destinada à classe dominante daquela destinada à classe trabalhadora, confirmando a posição de Luft (2000) de que "a educação escolar desde a sua origem foi um dos instrumentos-chave utilizados para naturalizar a sociedade de classes" (p. 119), por isto mesmo, sempre tomou o processo produtivo em curso como o referencial da quantidade e da "qualidade" (capacitação técnica) de educação a ser oferecida, isto é, a educação disponibilizada à classe trabalhadora se restringia a uma "cultura" mínima, e ao desenvolvimento de uma certa habilidade técnica, capaz de responder às necessidades do processo de industrialização.

Importante destacar uma contradição interna do sistema educacional brasileiro. As últimas cinco décadas foram marcadas por uma gradativa incorporação ao sistema educacional de contingentes populacionais anteriormente excluídos da escola. Segundo dados do censo escolar de 2000, realizado pelo Inep/MEC, dentre a população de sete a 14 anos, 97,0\% estão sendo atendidas pela escola, independente do nível de ensino, e $95,4 \%$ freqüentam o ensino fundamental. No entanto, o evidente crescimento do acesso ao ensino fundamental está longe de traduzir que o País instituiu um sistema educacional democrático onde todos entram e todos permanecem estudando. Primeiro, porque existe um contingente da ordem de aproximadamente $4,6 \%$ da população entre sete e 14 anos que continua sem ter garantido o acesso ao ensino fundamental; segundo, porque ainda que os indicadores de acesso à escola apontem um determinado crescimento, os indicadores da evasão e repetência, mesmo tendo melhorado, quando comparados a períodos anteriores, ainda assim continuam insatisfatórios. A taxa de repetência no ensino fundamental, na casa dos $21,6 \%$, combinada com uma evasão da ordem de $4,8 \%$ e uma defasagem idade/série que atinge $41,7 \%$, representam um universo de milhōes de alunos alijados do direito à educação.

Assim, exclusão escolar, entendida como resultante processual da exclusão social, ou seja, as condições que alimentam o nascimento da exclusão social, que são as desigualdades provenientes da estrutura de classes da sociedade, são as mesmas que provocam a evasão, a repetência e a defasagem idade/série no interior das escolas, além de muitas vezes cercear o acesso de enormes contingentes populacionais ao saber escolarizado. A exclusão escolar, portanto, surge como um desdobramento da contradição do sistema capitalista, que necessita do espaço educativo como instrumento de manutenção de sua lógica, que procura legitimar a dominação econômica através da dominação cultural, e que para tanto se utiliza da escola como mecanismo de mediação para assegurar a estrutura de classes da sociedade capitalista.

Os indicadores de acesso, repetência, evasão e defasagem idade/série, como mecanismos de exclusão escolar tornam ainda mais evidente a necessidade de implementação de políticas que democratizem e que superem o caráter seletivo e excludente da escola. 


\section{POLÍTICAS PÚBLICAS DE EDUCAÇÃO E A EXCLUSÃO ESCOLAR}

Numa sociedade em que as riquezas são criadas a partir de especulações totalmente abstratas, sem vínculos - ou com vínculos muito fracos - com investimentos produtivos (FORRESTER, 1997, p. 86), há indicação de que é a esfera financeira que comanda, cada vez mais, a repartição e a destinação social dessa riqueza (CHESNAIS, 1996, p. 15). E, nesse quadro, as políticas econômicas são reforçadoras da exclusão social.

As propostas de política econômica encontram sua expressão mais geral na tese do Estado mínimo. Mínimo que se traduz na "deterioração das políticas sociais, na incapacidade de conter o desemprego em massa, na baixa aplicaçáo de recursos públicos para a educação e a saúde, na contenção de gastos com os servidores públicos" (PINO, 2001, p. 73). Medidas, em geral, adotadas de forma autoritária, que Sader (1999, p. 126) prefere chamar de Estado mini-max: "máximo para o capital e mínimo para o trabalho". Máximo/forte na definição das estratégias de acumulação, assumindo o papel de gestor e legitimador das exigências do capitalismo global. Mínimo/fraco em todos os investimentos sociais e nas intervenções econômicas. Com isso, o Estado deixa de ser o mediador das exigências sociais e articulador das políticas econômicas, construindo o paradoxo do "menor governo" como sinônimo de "mais governo".

Bruno (1997, p. 24) observa que o Estado tem sido um aparelho instrumentalizado pela classe capitalista, desde sua origem, e que o elemento novo que se observa na contemporaneidade é o nível de concentração de capital pela classe capitalista, permitindo às maiores empresas relacionarem-se diretamente, assumindo as funções econômicas e políticas, secundarizando o papel do Estado como coordenador da atividade econômica. O processo decisório, situa a autora, deslocou-se da esfera do Estado Nacional para fora da estrutura formal, sendo o Estado acionado apenas para operacionalizar, implementar e legitimar juridicamente as decisões. Essa "informalidade", no entanto, não significa que a estrutura de poder seja frágil, ao contrário. Para a autora, trata-se de uma estrutura de poder multipolar, de abrangência supranacional, constituída pelos centros de decisão dos maiores grupos econômicos, os organismos internacionais, os organismos políticoadministrativos oriundos da esfera governamental e as grandes centrais sindicais burocratizadas (BRUNO, 1997, p. 23).

Muito embora a reforma dos anos de 1990 tenha especificidade própria, conjuntura única, Draibe (citada por AZEVEDO, 2002, p. 56) vê nas reformas do aparelho do Estado implementadas no Brasil a mesma justificativa de dotar o Estado de racionalidade técnica nas decisões e açõos públicas. Reformas que, continua a autora, viabilizaram a prática centralizada do planejamento, a intervenção estatal na economia e em outras esferas da vida civil, segundo os moldes que o capitalismo assumiu entre nós de conciliação de interesses arcaicos (patrimonialismo e clientelismo) e modernizantes (modernização conservadora).

Nesse modelo de gestão do Estado, Azevedo (2002) observa a busca de um "replanejamento institucional" inspirado no neoliberalismo, apregoado como única possibilidade de sobrevivência reservada pela história, e imputa ao Estado intervencionista, segundo Moraes (2002), duras críticas. Enfatizam que a ação do Estado, continua Moraes, inibe a mola propulsora do progresso, afeta a competitividade e gera desincentivos ao trabalho. 
Ao mercado é atribuída a supremacia na alocação de recursos, matriz da riqueza, eficiência e justiça. Justifica-se, assim, segundo Dourado (2002, p. 237), a necessidade de medidas de liberalização da economia, desregulamentação financeira, alterações substantivas na legislação previdenciária e trabalhista.

Nesse contexto, as demandas e necessidades que anteriormente eram consideradas, segundo Borón (2000), assunto público, direito do cidadão, transformam-se em bens, questōes individuais, subjugando seu usufruto ao poder de compra do usuário, restando ao governo apenas criar condições de oferta dessas demandas no mercado. $\mathrm{O}$ mesmo que privatização ou mercantilização dos direitos de cidadania, equivalente, para o autor, a "descidanização" de grandes setores sociais, em que a desigualdade é a norma e o desemprego contingência necessária.

A descentralização ou transferência para Estados e Municípios de grande parte da gestão de políticas sociais é, segundo Azevedo (2002), colocada como instrumento de modernização gerencial da gestão pública, possibilidade de promover a eficácia, mecanismo de correção das desigualdades educacionais, sinônimo de otimização dos gastos públicos. Descentralização essa, categorizada pela autora (2002, p. 55), como "economicista-instrumental", considerando que "local é considerado uma unidade administrativa a quem cabe colocar em ação políticas concebidas no nível do poder central”.

Assiste-se, assim, a re-significação da idéia de descentralização, que para Cury (2002, p. 177) era identificada pelas forças progressistas com aspiraçōes de maior participação nas decisões, associada a processos de democratização do espaço político, partilha do poder entre Estado e coletividade.

Pesa sobre as reformas do Estado no Brasil a justificativa de tornar mais eficiente o desempenho da máquina governamental e, conseqüentemente, garantir serviços de melhor qualidade para a população. Ocorre, porém, que os projetos apresentados guardam estreita vinculação com as exigências das agências reguladoras internacionais. Dourado (2002) aponta como interlocutores preferenciais nesse processo o Banco Interamericano de Desenvolvimento (BID) e agências da Organização das Nações Unidas e a atuação do Banco Mundial no processo de reestruturação e abertura da economia nos novos marcos do capital sem fronteiras. Em linhas gerais, essas reformas preconizam o livre mercado, o Estado mínimo e a liberdade de ação política e econômica dos indivíduos.

Também Oliveira (2001) vê nas políticas de educação em andamento essa mesma sintonia com as recomendações dos organismos internacionais, quando explicitam a intenção de oferecer um mínimo de conhecimentos capaz de ajustar a oferta de mão-de-obra e a demanda do mercado de trabalho, traduzidos no binômio educação e empregabilidade. Além disso, as propostas de universalização do acesso à educação são combinadas com medidas de racionalidade técnica para gestão de recursos, reduzindo o político ao distributivo. Trata-se, segundo a autora, de um perverso mecanismo para integrar a todos socialmente, garantindo a uns uma educação sólida - trabalhadores empregados e qualificados - e a outros os rudimentos necessários ao desempenho das atividades da economia informal e ao emprego. Reconhecer a existência desse perverso mecanismo de integração social ajuda, talvez, a explicar porque $98 \%$ das nossas crianças estão na escola e não estão aprendendo.

De acordo com o papel que o Estado assume frente à educação, as políticas públicas se apresentam traduzindo, em última instância, o projeto de sociedade que se deseja construir. 
Dentre os muitos estudos que procuram identificar o papel que o Estado apresenta no campo da educação, Gracindo (2001) sistematiza três possibilidades que, quase sempre, se apresentam interligadas: responsável, financiador e suplementador. No primeiro, o Estado assume diretamente a oferta da educação, via espaço público, comprometendo-se com o financiamento, acompanhamento e avaliação dessa prática social, dimensionando a educação como direito. No segundo, o Estado desenvolve ações que visam apenas financiar as políticas educacionais onde quer que elas aconteçam: quer no setor público, quer no setor privado. Nessa ótica, o Estado assume a concepção de educação como uma mercadoria sujeita ao mercado. No terceiro papel, o Estado tem a função de suplementar a ação da família, cobrindo apenas as necessidades dos mais carentes, implicando um sistema de ensino dual: público para atendimento das classes populares, e privado voltado para as elites.

As políticas públicas, no entanto, alerta a autora, devem ser entendidas como um movimento dialético resultante do confronto de interesses contraditórios que se alimentam, inclusive, dos movimentos sociais. Esse processo pode fazer do Estado espaço privilegiado de luta e afirmação das reivindicações populares.

A partir dos referenciais propostos pela autora, observa-se que o novo padrão de Estado, consoante com a atual fase de internacionalização do capital, em que o neoliberalismo passou a ditar o ideário e o programa a serem implementados no centro e na periferia do sistema, vai se tornar mais nítido no Brasil a partir de 1990, com destaque na era FHC, que, dada sua forma orgânica de atuação, faz permanecer muitas de suas diretrizes no atual governo. Projeto que começou a ser desenhado nos anos 80 e que foi, parafraseando Vieira (2000), "desenho cujo contorno não é linear e cuja lógica só aparece ao final do caminho percorrido”.

Especificamente no campo educacional as políticas públicas enfatizam a necessidade de um sistema educacional que se ajuste às demandas do mundo do trabalho, onde a educação deve promover a empregabilidade. Para Silva Junior (2002, p. 214) são as novas tecnologias que definem a nova formação do trabalhador e do cidadão, e o novo ser social deve conhecer simultaneamente o produto e o processo, possuir habilidades de gestão, espírito para o trabalho em equipe, e sensibilidade para refinar a qualidade do processo de trabalho, com base em saberes explícitos adquiridos.

É com base nesse paradigma que a nova LDB vai enfatizar o trinômio qualidade total, produtividade e eficiência e o Ministério da Educação vai nomear (AGUIAR, 2002, p. 75) uma série de açōes privilegiadas que incidem diretamente nas administraçōes estaduais, interferindo localmente na formulação e na condução de políticas educacionais das secretarias estaduais e municipais de educação.

Açóes que traduzem a perspectiva do reducionismo economicista, cujo escopo se centra na visão unilateral de custos e benefícios, cuja concepção de política assenta-se, segundo Dourado (2002, p. 240), na defesa da descentralização dos sistemas, no desenvolvimento das capacidades básicas de aprendizagem necessárias às exigências do trabalho flexível, na realocação de recursos públicos para a educação básica, na ênfase à avaliação e à eficiência que revelam, segundo o autor, o caráter utilitarista presente nas concepções do Banco Mundial para a educação.

Do exposto depreende-se que, em face da reestruturação produtiva as políticas públicas brasileiras, inclusive as de educação, foram reorientadas, a partir dos anos 1990, por 
uma reforma do Estado que alterou substancialmente os padrōes de intervenção estatal, redirecionando mecanismos e formas de gestão e em sintonia com os organismos multilaterais. Sintonia essa traduzida por Silva Junior (2002) como uma "intervenção consentida" realizada pelas autoridades, direcionadas por uma razão instrumental e pela busca do consenso social.

Nesse contexto, a política pública de educação aparece ocupando espaço estratégico no ideário neoliberal, como formação técnica para atender à produção capitalista e como meio de difusão das idéias liberais (AHLERTT, 2000, p. 40). Além disso, apresenta-se como possibilidade de reduzir as desigualdades sociais e meio de valorização do capital humano (AZEVEDO, 2001, p. 15-16) submetida, porém, aos deslocamentos resultantes da transposição das regras da economia para o todo social.

Nessa ótica, Gracindo (1997, p. 8) enumera alguns "deslocamentos" resultantes da definição, na realidade, de novos paradigmas, cuja essência deriva da subordinação do social à lógica do econômico. São eles: da quantidade para a qualidade (mercadológica); da centralização para a descentralização (desresponsabilização do Estado); do público para o privado (educação como mercadoria); do ensino superior para a educaçáo básica (com a privatização da educação superior - por fora e por dentro); das questôes políticas para as questōes pedagógicas (dando supremacia ao sentido técnico da educação).

Deslocamentos porque os compromissos assumidos com a educação de qualidade vinculam-se à eficiência e à otimização na aplicação dos recursos no sentido gerencial de atender localmente as demandas do cidadão-cliente através de mecanismos de descentralização da gestão que desresponsabilizam o Estado com as políticas educacionais transferindo para as comunidades o poder decisório, diferente, portanto, das reivindicaçôes pela redefinição das relaçōes de poder dentro do Estado. Assim, as políticas educacionais são definidas sob concepções de neutralidade política que a educação não possui. $\mathrm{O}$ político se presentifica quando coloca o cidadão como objeto da história, desvinculado do social, apático e individualista. Quando, também, enfatiza o ensino fundamental, desqualificando o ensino superior em nome da oferta universal do instrumental básico, comprometendo o pensar, essencial a qualquer projeto de desenvolvimento e de soberania nacional. E com esse mesmo arcabouço, algumas políticas públicas na área da educação têm sido desenvolvidas nos últimos anos, voltadas para aqueles que se situam em situação de pobreza.

Para Pastorini (2003, p. 214), esse "novo paradigma de políticas públicas" subverte a seletividade em focalização e a universalidade em garantia de igualdade no tratamento e acesso a programas e serviços a todos aqueles que se encontram numa mesma situação de pobreza. Para a autora, programas sociais emergenciais, assistencialistas, focalizados para os "bolsões de pobreza", adoção de critérios de elegibilidade rígidos e perversos para selecionar os destinatários dos programas e das ações focalizadas são componentes desse mesmo quadro.

A educação aparece como mecanismo fundamental na construção/imposição desse referencial que assegure a competitividade, garanta a flexibilidade do mercado de trabalho e a subordinação da política social à política econômica, como racionalidade instrumental concorrencial (BONETI, 2001, p. 21), onde o mercado funciona como regulador da esfera econômica e social. 
Importante indicar que analisar políticas públicas implica identificar a sua forma concreta de interferir no real, isto é, uma política é identificada, sobretudo, nos programas, projetos e leis que são colocadas em ação por um dado governo, como agente gestor do Estado. Nesse sentido, situando apenas a educação básica, dentre os programas educacionais de atendimento à população carente, com o objetivo de inserir e manter essa população no sistema educacional, destacam-se: Programa Nacional de Alimentação Escolar e Merenda Escolar, Programa Nacional do Livro Didático, Programa Nacional de Transporte Escolar e o Programa Nacional de Saúde do Escolar.

Além dos programas descritos, verifica-se que no Brasil são diversas as propostas de garantia de renda mínima em discussão e implantação que visam substituir as políticas tradicionais por uma compensação monetária, diretamente outorgada a uma populaçãoalvo, exigindo algumas contrapartidas, inclusive no campo da educação. Programas que, para Draibe (1998, p. 208),

com variaçōes de ênfase, têm como objetivo a melhoria das condições de vida daqueles que constituem seu público-alvo por excelência - as crianças e adolescentes. Além da complementação monetária, cada programa busca comprometer os pais ou responsáveis com a frequiência das crianças à escola, com o atendimento regular à saúde e com a sua não-permanência nas ruas.

Um dos programas com essa formatação é o Programa Bolsa Escola Federal (PBEF), que visa beneficiar famílias carentes cujas crianças de 7 a 14 anos estejam matriculadas no Ensino Fundamental, com um benefício de R \$ 15,00 mensais por aluno, até o limite máximo de três crianças por família, atingindo um valor máximo de $\mathrm{R} \$ 45,00$, com o objetivo de assegurar a permanência dessas crianças na escola.

Vale assinalar que pesquisa sobre esse tema (MARQUES, 2004) identificou que o PBEF, durante a gestão Paulo Renato de Sousa no Ministério da Educação, assentou-se sobre a concepção de que o fracasso escolar está concentrado no aluno, nas condições sócio-econômicas vivenciadas pelo educando como elementos impeditivos do seu sucesso escolar, dado que o Programa resumia sua atuação ao pagamento de benefício aos alunos carentes e ao incentivo às açóes educativas complementares. A partir de 2002, durante a gestão Cristovam Buarque no Ministério da Educação, a concepção do programa começou a ser redefinida com uma proposta de repensar a cultura de seletividade, na medida em que passou a propugnar a prática pedagógica como diálogo relacional que possibilita a construção de uma cultura fundada na educação como direito de todos.

O desafio proposto na implementação do Programa Bolsa Escola Federal é o da inclusão educacional, inclusive daqueles que representam o déficit histórico do analfabetismo, numa perspectiva inclusiva e democrática, permeada de sentido de coletividade e eqüidade. Significa, no dizer de Arroyo (2000, p. 38), reeducar olhares acostumados a uma perspectiva de titulação e credenciamento da escola, mecanismo de "seleção da força de trabalho, de status social, de empregos diferentemente remunerados, de empregabilidade no sentido de uma concepção mais humanista de educação orientada para o pleno desenvolvimento humano dos educandos".

O Programa Bolsa-Escola Federal pode ser entendido como um programa que se insere na idéia de garantia de renda mínima. Nesse sentido, vale indicar que os debates 
acerca desse tipo de programas surgiram na esteira da crise do Estado do Bem-Estar Social, da crise salarial provocada pelo desemprego e as novas relações de trabalho, ocorrida especialmente na Europa. Crise essa que agravou os problemas sociais, elevando o grau de demandas sociais e, simultaneamente, reduzindo os recursos públicos e privados disponíveis para o gasto social. Imprimiu, assim, um novo pensar às políticas educacionais, assumindo características específicas.

Discutir, pois, programas de renda mínima, significa identificar estratégias que possam minimizar a situação de pobreza, considerando-se que as políticas compensatórias ou de assistência social tradicional, no Brasil, mostraram-se, segundo Ramos (1997, p. 23), historicamente: (a) incapazes de melhorar as condições de vida das populações marginalizadas; (b) de elevada relação custo/benefício; e (c) favoráveis ao uso clientelista dos recursos financeiros.

Entendendo, no entanto, que "propor mínimos sociais é estabelecer o patamar de cobertura de riscos e de garantias que uma sociedade quer garantir a todos os seus cidadãos" (SPOSATI, 2001, p. 10), obriga a definição de um ideal de cidadania e solidariedade, que a autora chama de "padrão societário de civilidade", baseado num critério igualitário para a distribuição de recursos, produtos e serviços.

Caminhando na mesma direção Draibe $(1989$, p. 4) afirma que as políticas de garantia de renda mínima, fundadas na igualdade de resultados, baseiam-se num critério igualitário de redistribuição, um "direito que deve ser garantido a todos os cidadãos, independentemente de qualquer condicionante prévio". Indica, ainda, que atender ao ideal de igualdade de oportunidades significa respeitar as "diferenças", legitimar a desigualdade, reforçar as condições sociais prévias e presentes que definem as diferenças de renda e de condiçōes sociais.

Num olhar mais acurado das açôes desse gênero, verifica-se que os programas de renda mínima supõem ora a substituição de programas sociais por uma transferência financeira com ênfase no mercado, ora uma proposta progressiva no campo da inclusão e da afirmação da cidadania. Colocar-se em uma ou outra opção depende do programa adotado, do seu horizonte, das relaçôes de interface que estabelece com outras políticas sociais.

Ao analisar o conceito de mínimo nas políticas públicas de educação, vale rever a posição de Pereira (2002, p. 26), segundo a qual há que se fazer também uma diferença entre mínimo e básico, que, para ela, são conceitos distintos, pois, "enquanto o primeiro tem a conotação de menor, de menos, em sua acepção mais ínfima, identificada com patamares de satisfação de necessidades que beiram a desproteção social, o segundo não". O básico nos remete a algo fundamental, principal, primordial. Enquanto mínimo pressupõe supressão ou cortes de atendimentos, tal como propõe a ideologia liberal sob alegado respeito a preferências, que são individuais e relativas, o básico requer investimentos sociais de qualidade.

Para a autora, o mínimo submete a racionalidade coletiva de bem-estar à lógica privatista do mercado; trata-se de proporcionar aos pobres a pior proteção social. Concepção que no Brasil mereceu do Instituto de Estudos Políticos e Sociais, coordenado por Jaguaribe (1986, p. 29-30), o chamado compromisso minimax que: 
representa o nível de coincidência entre os máximos esforços e sacrifícios que os estratos mais abastados da sociedade se disponham a assumir, de forma basicamente consensual, em favor da paz social e da elevação do padrão de vida das massas, e os benefícios mínimos que os estratos mais pobres da sociedade se disponham também de forma basicamente consensual, a aceitar como um teto para as suas reivindicaçōes, em favor de uma garantida e continuada elevação de seu próprio padrão de vida, de capacitação e de participação e, por via de conseqüência, da preservação da paz social.

Para Sposati (2003, p. 20), nessa mesma linha de raciocínio, "adotar a conduta minimalista é incorrer em uma concepção reducionista que toma, por referência, a vida no limiar da subsistência biológica". A questão é que ser cidadão transcende o ser biológico, vincula-se ao compromisso com a preservação da vida humana e o desenvolvimento da autonomia, como parâmetro social básico de inclusão. Com isso, a autora lembra que a discussão de mínimos sociais, numa concepção de padrão básico de inclusão, "deve ser conduzida para o interior do processo inclusão-exclusão social”, tensão contínua, cuja força motriz é a construção de um projeto civilizatório novo, embasado na solidariedade (2003, p. 31).

Assim, o que se verifica nos programas desenvolvidos no campo da educação que visam acesso, permanência e sucesso na escolaridade, a partir de uma renda suplementar, e que, em tese, gerariam a diminuição da exclusão escolar, é que eles não conseguiram sanar o problema da reprovação, evasão e segregação de estudantes no interior da escola (MARQUES, 2004). Isto porque são programas que incorporam a visão de mínimo como padrão básico de inclusão social, além de serem descolados de uma política global de erradicação da pobreza. São, portanto, como advertiu Lopes (1997, p. 159), ao analisar as políticas de atendimento às demandas populares, medidas paliativas que não interferiram na estrutura das relações de trabalho e distribuição de renda, base das desigualdades sociais.

Um aspecto, no entanto, cabe ser aqui indicado como uma possibilidade de construção de uma educação inclusiva: a gestão democrática da educação. Certamente, apenas a instituição de relações democráticas da escola e nos sistemas de ensino não é suficiente para a superação dos determinantes de exclusão, próprios de uma sociedade de classes, "porém, qualquer passo em frente para a democratização do ensino faz parte de um todo econômico e social, que prova ter se atingido uma fase progressista" (SNYDERS, 1976, p. 67). E atingir essa fase progressista não significa, conforme Snyders (1976), alterar a natureza da estrutura social vigente, não significa um processo de profundas rupturas, mas também não se pode desconsiderar dentro do espaço de inúmeros movimentos necessários, que deverão ser feitos até que se alcancem as condiçôes para as mudanças estruturais exigidas para a construção de uma sociedade sem explorados e exploradores, berço de uma escola inclusiva que gerará a emancipação humana. 


\section{Notas}

1. Construto apresentado por Althusser.

2. Conceito desenvolvido por Bourdieu e Passeron.

\section{Referências}

AGUIAR, Marcelo. Relatório do Seminário Internacional Bolsa-Escola. Brasília: MEC, 2002a.

.; ARAÚJO, Carlos Henrique. Bolsa-escola: educação para enfrentar a pobreza. Brasília: Unesco, 2002b. AHLERT, Alvori. Exclusão social versus qualidade ética da educação. In: BONETI, Lindomar Wessler (Coord.). Educação, exclusão e cidadania. Ijuí: Unijuí, 2000, p. 39-64.

ANDERSON, Perry. Balanço do neoliberalismo. In: SADER, Emir; GENTILI, Pablo (Orgs.). Pós-neoliberalismo: as políticas sociais e o Estado democrático. Rio de Janeiro: Paz e Terra, 2000. p. 9-23.

ANTUNES, Ricardo. Adeus ao trabalho? Ensaios sobre as metamorfoses e a centralidade do mundo do trabalho. São Paulo: Cortez, 1995.

. Os sentidos do trabalho: ensaio sobre a afirmação e a negação do trabalho. São Paulo: Boitempo, 2000.

Reestruturação produtiva e mudanças no mundo do trabalho numa ordem neoliberal. In: DOURADO, Luiz Fernandes. Políticas públicas e educação básica. São Paulo: Xamã, 2001. p. 13-27.

ARROYO, Miguel Gonzalez. Fracasso-sucesso: o peso da cultura escolar e do ordenamento da educação básica. In: ABRAMOWICZ, Anete; MOLL, Jaqueline (Orgs.). Para além do fracasso escolar. São Paulo: Papirus, 2000a. p. 11-26.

. Fracasso-sucesso: um pesadelo que perturba nossos sonhos. Em Aberto, Brasília, v. 17, n. 71, p. 3340, jan. 2000b.

AZEVEDO, Janete. Educação como política pública. São Paulo: Autores Associados. 2001a. (Coleção Polêmicas do Nosso Tempo).

O Estado, a política educacional e a regulação do setor educação no Brasil: uma abordagem histórica. In: AGUIAR, Márcia Ângela da Silva; FERREIRA, Naura (Orgs.). Gestão da educação: impasses, perspectiva e compromissos. São Paulo: Cortez, 2001b. p. 17-42.

Implicações da nova lógica de ação do Estado para a educação municipal. Educação e Sociedade, Campinas: Cedes, v. 23, n. 89, p. 49-71, set. 2002.

BONETI, Lindomar Wessler. Estado e exclusão social hoje. In: ZARTH, Paulo Afonso et al. Os caminhos da exclusão social. Ijuí: Edunijuí, 1998. p. 9-44. (Coleção Ciências Sociais).

. As Política Educacionais, a Gestão da Escola e a exclusão social. In: AGUIAR, Márcia Ângela da Silva; FERREIRA, Naura (Orgs.). Gestão da Educação: impasses, perspectivas e compromissos. 2. ed. São Paulo: Cortez, 2001. p. 213-241.

BORÓN, Atílio. A sociedade civil depois do dilúvio neoliberal. In: SADER, Emir; GENTILI, Pablo (Orgs.). Pós-neoliberalismo: as políticas sociais e o Estado democrático. Rio de Janeiro: Paz e Terra, 2000. p. 63-118.

BRUNO, Lúcia. Poder e administração no capitalismo contemporâneo. In: OLIVEIRA, Dalila Andrade (Org.). Gestão democrática da educação: desafios contemporâneos. Petrópolis: Vozes, 1997. p. 15-45.

BUARQUE, Cristovam. O que é apartação: o apartheid social no Brasil. São Paulo: Brasiliense, 1999. (Coleção Primeiros Passos).

CASTEL, Robert. As metamorfoses da questão social: uma crônica do salário. Petrópolis: Vozes, 2001. . et al. As armadilhas da exclusão: desigualdade e a questão social. São Paulo: Educ, 2000.

CHESNAIS, François. A mundialização do capital. Trad.: Silvana Finzi Foá. São Paulo: Xamã, 1996.

CURY, Carlos Roberto Jamil. A educação básica no Brasil. Educação e Sociedade, Campinas: Cedes, v. 23, n. 80, p. 169-201, 2002.

D'AVILA, José Luiz Piotto. A crítica da escola capitalista em debate. Petrópolis: Vozes; Ijuí: Fundação de Integração, Desenvolvimento e Educação no Noroeste do Estado, 1985. 
DOURADO, Luiz Fernandes. Reforma do Estado e as Políticas para a Educação Superior no Brasil nos anos 90. Educação e Sociedade, Campinas: Cedes, v. 23, n. 80, p. 235-253, 2002.

DRAIBE, Sônia M. As políticas sociais brasileiras: diagnósticos e perspectivas. In: IPEA. Prioridades e perspectivas de políticas públicas para a década de 90. V. 4. Brasília: Ipea, 1989.

et al. Programas de Renda Mínima para Famílias Carentes: levantamento das experiências e metodologia de avaliação. In: LOBATO, Ana Lúcia (Org.). Garantia de renda mínima: ensaios e propostas. Brasília: Ipea, 1998. p. 203-250.

ESCOREL, Sarah. Vidas ao léu: uma etnografia da exclusão social. 1998. 290 f. Tese (Doutorado em Sociologia) Departamento de Sociologia, Universidade de Brasília, Brasília.

FERREIRA, Aurélio Buarque de Holanda. Novo Aurélio século XXI: o dicionário da língua portuguesa, Rio de Janeiro: Nova Fronteira, 1999.

FORRESTER, Viviane. O horror econômico. Trad. Álvaro Lorencini. São Paulo: Edunesp, 1997.

GRACINDO, Regina Vinhaes. Estado, sociedade e gestão da educação: novas prioridades, novas palavras-de-ordem e novos velhos problemas. Revista Brasileira de Política e Administração da Educação, v. 13, n. 1, p. 8-18, jan./jun. 1997.

.; BORDIGNON, Genuíno. Gestão da educação: o município e a escola. In: AGUIAR, Márcia Ângela

da Silva; FERREIRA, Naura (Orgs.). Gestão da educação: impasses, perspectivas e compromissos. São Paulo: Cortez, 2001. p. 147-176.

HAYEK, Friedrich. August Von. O caminho da servidão. Trad.: Anna Maria Capovilla, José Ítallo Stelle e Liane de Moraes Ribeiro. Rio de Janeiro: Instituto Liberal, 1990.

HELD, David; McGREW, Anthony. Prós e contras da globalização. Trad.: Vera Ribeiro. Rio de Janeiro: Zahar, 2001. HOBSBAWM, Eric John. A era do capital. Rio de Janeiro: Paz e Terra, 1979.

. A era das revoluçôes. Rio de Janeiro: Paz e Terra, 1982.

. A era dos extremos: o breve século XX - 1914-1991. São Paulo: Companhia das Letras, 1995.

IBGE. Censo. Brasília, 2000.

IBGE. PNAD. Brasília, 2003.

IBGE. Sintese dos Indicadores Sociais. Brasília, 2004.

INEP. Censo Escolar. Brasília, 2000.

JAGUARIBE, Hélio et al. Brasil 2000: para um pacto social. Rio de Janeiro: Paz e Terra, 1986.

LOPES, José Rogério. A instituição dos Programas de Garantia de Renda Familiar Mínima - PGRFM: críticas e apontamentos. In: SPOSATI, Aldaiza (Org.). Renda mínima e crise mundial: saída ou agravamento. São Paulo: Cortez, 1997. p. 155-173.

LUFT, Hedi Maria. O paradoxal papel da escola: promete incluir, excluindo. In: BONETI, Lindomar Wessler. Educação, exclusão e cidadania. Ijuí: Edunijuí, 2000. p. 117-124.

MARQUES, Sonirza Corrêa. Programa Bolsa-Escola Federal: limites e possibilidades de uma política pública. Dissertação de Mestrado, PPGE/UnB, Brasília, 2004.

MARTINS, José de Souza. Exclusão social e a nova desigualdade. São Paulo: Paulus, 1997.

MARX, Karl. Miséria da filosofia. Porto: Escorpião, 1976.

. Trabalho alienado e superação positiva da auto-alienação humana. In: FERNANDES, Florestan (Org.). Marx e Engels. São Paulo: Ática, 1984a. p. 146-181 (Coleção Grandes Cientistas Sociais, 36).

O capital: crítica da economia política. Livro 1, v. 2. Trad.: Reginaldo Sant’Anna. São Paulo: Difel, 1984b.

MORAES, Reginaldo Carmello Corrêa de. Reformas neoliberais e políticas públicas: hegemonia ideológica e redefinição das relações Estado-sociedade. Educação e Sociedade. Campinas: Cedes, v. 23, n. 80, p. 13-24, 2002.

NASCIMENTO, Elimar. Exclusão social: as múltiplas dimensōes do fenômeno. Brasília: UnB, 1994 (Série Sociológica, 111).

OLIVEIRA, Dalila Andrade. Política educacional nos anos 1990: educação básica e empregabilidade. In:

DOURADO, Luiz Fernandes; PARO, Vitor Henrique (Orgs.). Políticas públicas e educação básica. São Paulo: Xamã, 2001. p. 105-121.

PAIVA. Olgamir Amância Ferreira de. Gestão democrática e exclusão escolar: reflexos de uma política pública. Dissertação de Mestrado, PPGE/UnB, Brasília, 2002. 
PASTORINI, Alejandra. Intervenções públicas para atender a pobreza e o assistencialismo na Era FHC. Ser Social: Revista do Programa de Pós-Graduação em Política Social da Universidade de Brasília. Departamento de Serviço Social, v. 1, n. 1, p. 191-220, 2003.

PATTO, Maria Helena Souza. A produção do fracasso escolar. história de submissão e rebeldia. São Paulo: Casa do Psicólogo, 1999.

PAUGAN, Serge. Por uma sociologia da exclusão: o debate com Serge Paugan. Ed. Maura Pardini Bicudo Véras. São Paulo: Educ, 1999.

PEREIRA, Potyara Amazoneida. Necessidades humanas: subsídios à crítica dos mínimos sociais. São Paulo: Cortez, 2002.

PINO, Mauro Del. Política educacional, emprego e exclusão social. In: GENTILI, Pablo; FRIGOTTO, Gaudêncio (Orgs.). A cidadania negada. São Paulo: Cortez, 2001. p. 65-88.

RAMOS, Marlene de A. O Programa Bolsa-Escola Familiar para a educação no Distrito Federal: um estudo no Paranoá. Dissertação de Mestrado, PPGE/UnB, Brasília, 1997.

SADER, Emir. Estado e democracia: os dilemas do socialismo na virada do século. In: .; GENTILI, Pablo (Orgs.). Pós-neoliberalismo II: que Estado para que democracia? Petrópolis: Vozes, 1999. p.120-130.

SAWAIA, Bader et al. (Orgs.). As artimanhas da exclusão social: análise psicossocial e ética da desigualdade social. Rio de Janeiro: Vozes, 2001.

SILVA, Cármem Duarte da et al. De como a escola participa da exclusão social: trajetória de reprovação das crianças negras. In: ABRAMOWICZ, Anete; MOLL, Jacqueline (Orgs.). Para além do fracasso escolar. São Paulo: Papirus, 2000. p. 27-46.

SILVA JUNIOR, João dos Reis. Mudanças estruturais no capitalismo e a política educacional do governo FHC: o caso do ensino médio. Educação e Sociedade, Campinas: Cedes, v. 23, n. 80, p. 203-234, 2002. ISSN 0101-7330.

SNYDERS, Georges. Escola, classe e luta de classes. Trad.: Maria Helena Albarran. 2. ed. São Paulo: Centauro, 1976. SPOSATI, Aldaiza. Sobre os programas brasileiros de garantia de renda mínima - PGRM. In: Renda minima e crise mundial: saída ou agravamento. São Paulo: Cortez, 1997. p. 109-154. (Org.). . Globalização da economia e processos de exclusão social: capacitação em serviço social e política social, crise contemporânea, questão social e serviço social. Brasília: Cead, 1999. . Exclusão social e fracasso escolar. Em Aberto, Brasília, v. 17, n. 71, p. 21-32, jan. 2001. . et al. Assistência na trajetória das políticas sociais brasileiras: uma questão em análise. São Paulo: Cortez, 2003. VIEIRA, Sofia Lerche. Políticas educacionais em tempos de transiçāo. Brasília: Plano, 2000. 


\section{Contradiction exclusion/inclusion in society and in the school}

Abstract

With the understanding that social inequality and income concentration is increasing in Brazil and assuming even more perverse forms of social exclusion, the present article aims to reflect on the process of exclusion in society in general, and in education, in particular. In that sense, it tried to identify some interpretations given to the term exclusion, identifying it as a contradiction in the historical movement of the capitalist system. Moreover, it searched to verify how this contradiction implanted in modern times, manifests itself in the field of education, mainly at the end of the 20th century and beginning of the 21st century. As in the State global public policies, it identified the meaning underlying exclusion in educational policies, as a mediating instrument to maintain the social class structure of the capitalist society. In the search to identify public policies of basic education which aim at social inclusion, some programs appear to be created to care for the low class population, geared towards inserting and keeping this population in the educational system, with emphasis on the Federal Program "Bolsa-Escola" that characterizes itself as an action to guarantee minimum income.

Keywords: Social exclusion. School Exclusion. Public policies. Educational policies.

\section{Contradiction exclusion/inclusion dans la société et à l'école}

\section{Résumé}

Partant de la compréhension que l'inégalité sociale et la concentration du revenu au Brésil saccentuent et assument des formes devenant de plus en plus perverses d'exclusion sociale, cet article a comme objectif réfléchir sur le processus d'exclusion dans la société, en général, et dans l'éducation en particulier. A cet effet, il tente d'identifier quelques interprétations données au terme exclusion, en l'identifiant comme une contradiction dans le mouvement historique du système capitaliste. En plus, il cherche à vérifier comment cette contradiction, implantée dans les temps modernes, se manifeste dans le champs de l'éducation et surtout en fin du siècle XX et début du siècle XXI. Telle comme dans le cas des politiques publiques globales de l'État, il identifie le sens de l'exclusion sousjacente aux politiques d'éducation, comme instrument de médiation pour appuyer la structure de classes de la société capitaliste. En procurant identifier les politiques publiques d'éducation de base qui visent l'inclusion sociale, surgent quelques programmes qui prétendent donner une réponse à la population de bas niveau ayant comme objectif d'insérir et maintenir cette population dans le système éducationnel, mettant l'enfase sur le Programme Fédéral Bourse-École qui se présente comme une action pour garantir le salaire minimum.

Mots clefs : Exclusion sociale. Exclusion scolaire. Politiques publiques. Politiques d'éducation.

\section{La contradicción exclusión/inclusión en la sociedad y en la escuela}

\section{Resumen}

Con el entendimiento de que la desigualdad social y la concentración de renta en Brasil se sigue acentuando y tomando formas cada vez más perversas de exclusión social, el presente artículo tiene como objetivo reflexionar acerca del proceso de exclusión en la sociedad, en general, y en la educación, en particular. Para eso, intentó identificar algunas interpretaciones dadas al término exclusión, identificando-lo como una contradicción en el movimiento histórico del sistema capitalista. Además de eso, buscó verificar como esa contradicción que se implanta en la modernidad se manifiesta en los campos de la educación, sobretodo al final del siglo XX y al inicio del siglo XXI. Tal como en las políticas públicas globales del estado, se identificó el sentido de exclusión subyacente a las políticas de educación como instrumento de mediación para asegurar la estructura de clases de la sociedad capitalista. Buscando identificar politicas públicas de educación básica que visen la inclusión social, surgen algunos programas voltados para el atendimiento a la población carente, con el objetivo de insertar y mantener esa población en el sistema educacional, con destaque para el Programa Bolsa-Escuela Federal, que se conforma como una acción para garantizar renta mínima.

Palabras-clave: Exclusión social. Exclusión escolar. Políticas públicas. Políticas de educación. 
